\title{
An organizing region in metamorphosing hydrozoan planula larvae - stimulation of axis formation in both larval and in adult tissue
}

\author{
MELANIE STUMPF ${ }^{1,2}$, BRITTA WILL ${ }^{1,3}$, KAROLA WITTIG $^{1,4}$, JENNIFER KASPER ${ }^{1,5}$, BENJAMIN FISCHER ${ }^{1,6}$, \\ JÜRGEN SCHMICH ${ }^{1,7}$, STEFANIE SEIPP ${ }^{1,8}$ and THOMAS LEITZ*,1 \\ ${ }^{1}$ Entwicklungsbiologie der Tiere, Fachbereich Biologie, Technische Universität, Kaiserslautern, Germany, ${ }^{2}$ Bluestone Laboratory, \\ UCSF Diabetes Center, San Francisco, USA, ${ }^{3}$ Harvard Institutes of Medicine, Tenen Lab, Boston, USA, ${ }^{4}$ Institut für Experimentelle \\ und Klinische Pharmakologie und Toxikologie, Medizinische Fakultät Mannheim der Universität Heidelberg, Mannheim, Ger- \\ many, ${ }^{5}$ Klinikum der Johannes Gutenberg-Universität Mainz, Institut für Pathologie, Germany, ${ }^{6}$ Affenstein 6, Dirmstein, Ger- \\ many, ${ }^{7}$ R.O.S.E. Europe GmbH, Frankfurt am Main, Germany and ${ }^{8}$ Carl Roth GmbH + Co. KG, Karlsruhe, Germany
}

\begin{abstract}
A novel wingless gene was isolated from the marine colonial hydroid Hydractinia echinata. Alignments and Bayesian inference analysis clearly assign the gene to the Wnt5A group. In line with data found for the brachyury ortholog of Hydractinia, He-wnt5A is expressed during metamorphosis in the posterior tip of the spindle-shaped planula larva, suggesting that the tip functions as a putative organizer during metamorphosis. Additionally, the outermost cells of the posterior tip are omitted from apoptosis during metamorphosis. In order to investigate this putative organizer function, we transplanted the posterior tip of metamorphosing animals into non-induced larvae and into primary polyps $24 \mathrm{~h}$ and $48 \mathrm{~h}$ of age. In larvae, the tip induced formation of a secondary axis. In polyps the building of ectopic head structures was induced. Based on our data on axis formation, on gene expression similar to the organizers of other species, and the absence of regular apoptosis, we conclude that the posterior tip of the Hydractinia larva has organizing activity during metamorphosis.
\end{abstract}

KEY WORDS: Hydractinia echinata, planula larva, wnt, brachyury, organizer

\section{Introduction}

The organizer concept dates back to Spemann and Mangold (1924; see newly edited and corrected version of the paper published in Int. J. Dev. Biol. (2001) 45: 13-38; also see Sander and Faessler, 2001) who made their pioneering experiments of transferring the upper blastopore lip of an amphibian embryo to the opposite site of a host blastula. During gastrulation, the donor tissue induces and "organizes" a second, ectopic axis, i.e. a Siamese Twin develops. Organizing regions during gastrulation have been found in a wide variety of animal species (Lemaire and Kodjabachian 1996; Niehrs 2001, 2004; Robb and Tam 2004 for review). An organizing centre in the head has been found even earlier in the diploblast freshwater polyp hydra, a lower phylum Cnidaria (Browne 1908, Hobmayer et al. 2000, Rentzsch et al. 2007). This reference cnidarian species exhibits an organizing center in the hypostome. Transplanting the mouth region onto nearly any part of the gastric region of another polyp induces the development of a secondary axis with head, mouth and gastric region (Browne 1908). Although hydra is mainly investigated as a model for Cnidaria, it does not exhibit the whole life cycle of most other Cnidaria, where metagenesis occurs. In most cases, medusae bud asexually from a colony or from solitary polyps and give rise to gametes which are spawned into the water column. In the species investigated by us, the marine hydrozoan Hydractinia echinata (Müller and Leitz 2002 for a review), the medusae are reduced to sessile gonozoids which develop gonophores releasing their

\footnotetext{
Abbreviations used in this paper: BrdU, Bromodeoxyuridine; He, Hydractinia echinata; p.i., post induction; RACE, rapid amplification of cDNA-ends; TA cloning, cloning by Taq polymerase; TUNEL, TdT-mediated dUTP-biotin nick end labeling.
}

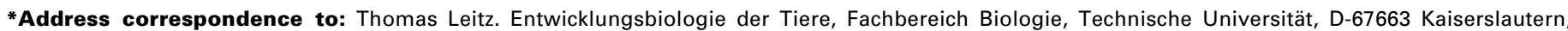
Germany. Fax: +49-631-205-4090.e-mail: leitz@biologie.uni-kl.de
} 
sexual products into the water column. A spindle shaped larva develops within 2-3 days, which then metamorphoses into an adult sessile polyp upon an external stimulus. During metamorphosis, the anterior blunt end of the larva fixes to the substratum with the pointed tip erected into the water. The posterior part contracts and the body experiences a shortening by contraction and apoptosis (Seipp et al. 2001). One day after the induction of metamorphosis a primary polyp has developed with a head and tentacles at the former posterior part of the larva. The basal plate with tube-like structures, the so-called stolons, derives from the former anterior part of the larva. Metamorphosis is naturally induced by environmental bacteria (Müller 1969; Leitz and Wagner 1993), but can also be induced experimentally by artificial inducers like phorbol esters, diacyglycerols, and certain ions like e.g. Cs ${ }^{+}$(Leitz 1997; Seipp et al. 2007, for review).

In a PCR-based search, we found a member of the wingless (wnt) gene family (Kusserow et al. 2005), reported to be involved in organizer signalling (Hobmayer et al. 2000; Niehrs 2001; Guder et al. 2006; Lee et al. 2006). Wingless proteins are known to play a role in the establishment of body axes, in particular in the establishment of the Spemann organizer in Xenopus, and in the subsequent patterning of the gastrulating embryo (Niehrs 2004). They also regulate many other aspects of metazoan development like stem cell fate and tumorigenesis. Members of the family activate signal transduction cascades by interacting with receptors of the Frizzled seven-pass transmembrane protein family (Logan and Nusse 2004). A secreted Wnt signal is transduced through one of the three signalling pathways, the canonical Wnt/ $\beta$-catenin pathway, the Wnt/planar cell polarity (PCP) pathway, or the Wnt/Ca ${ }^{2+}$ pathway (Nusse 2005). The T-Box transcription factor brachyury is involved in mesoderm differentiation (Smith 1999). A brachyury ortholog (like Wnt: Hobmayer et al. 2000) is expressed in Hydra in the hypostome and in buds at an early stage in the region of the future hypostomes (Technau and Bode 1999; Bielen et al. 2007). Its Hydractinia echinata ortholog, Hech-Bra, was isolated and identified by Kroiher (1999) and found to be expressed at the posterior tip of Hydractinialarvae. We characterized the expression pattern of He-Wnt and Hech-Bra by in situhybridization and found them to be expressed both at the posterior tip of Hydractinia larvae. In order to elucidate the potential organizing activity of this He-Wnt/Hech-Bra expressing region, we did a series of transplantation studies using the posterior tips of metamorphosing larvae and indeed found strong evidence for a putative organizing function. Given the idea that planula-like creatures are most probably the metazoan ancestor (Yanze et al. 2001), we discuss our findings in the light of evolution of the organizing region.

\section{Results}

\section{Identification of a Wnt ortholog in Hydractinia echinata}

Database analysis of the putative amino acid sequence arranged the clone to the Wnt-family, especially to the Wnt1 signalling protein family. The so called He-wnt (Hydractinia echinata wingless) protein contains a Wnt-protein signature at amino acids 204-208.

Further analysis of the protein sequence showed $41 \%-43 \%$ identity (62\% similarity) to a Wnt5A-glycoprotein of human, rat, Xenopus, mouse and $41 \%$ identity (60\% similarity) to a Wnt5B of human or mouse, respectively.

A multiple alignment is shown in Fig. 1. As compared to known wingless proteins in cnidaria and other metazoa, the isolated sequence is most similar to the Wnt protein of the ascidian Halocynthia roretziand clusters within the Wnt 5 or $5 \mathrm{~A}$ group, respectively (Fig. 2). Because of its clear relationship to the wnt5A group, we have named the gene $\mathrm{He}$-wnt5A.
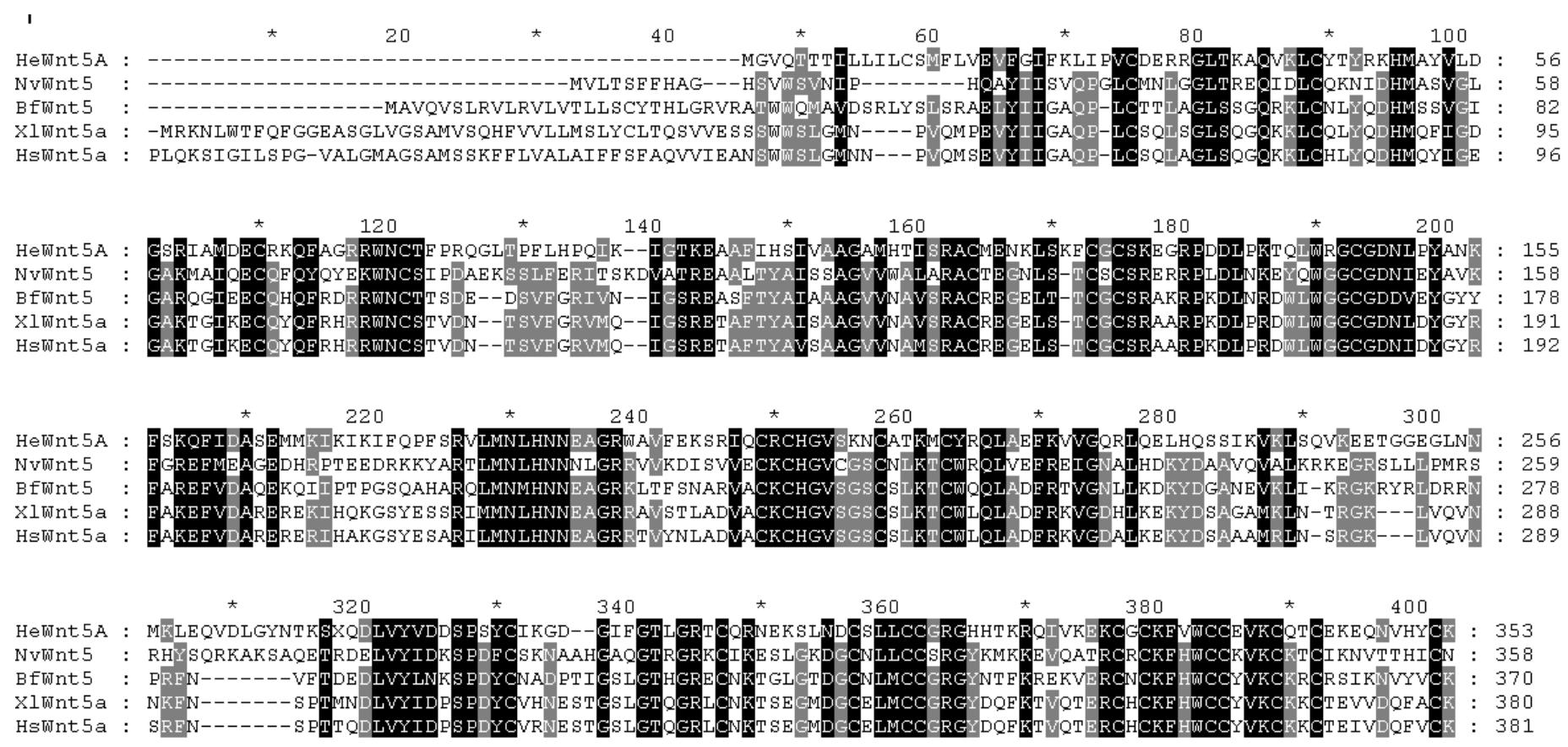

Fig. 1. Alignment of the novel He-Wnt5A with known Wnt protein sequences. 
In situ location of He-wnt5A expression in metamorphosing larvae with respect to apoptotic removal of larval tissue

In situ hybridization revealed an expression of $\mathrm{He}$ $w n t 5 A$ in the outermost posterior tip of animals approx. 3 hours post induction (Fig. 3A, arrow), with few other isolated cells in the posterior half (examples: arrowheads). Signals were found to be located in the ectoderm of the metamorphosing planula. First signals could be seen in animals of stage 5 ( $1 \mathrm{~h}$ p.i.) and remained at the same location during metamorphosis until gene expression could be found in the developing hypostome of the young polyp (24h p.i.) (data not shown). The darker staining of the anterior entoderm results from a 3D effect of the whole-mount specimen and does not represent wingless positive signals. The same expression pattern could be found for Hech-bra, (Hydractinia echinata brachyury ortholog) which occurred first at the posterior tip (Fig. 3B) of stage 5 (1h p.i.) during metamorphosis up to the early hypostome. Both genes are not expressed in non-induced larvae (not shown). According to previous data, however, large amounts of the larval cells are known to be removed during metamorphosis by apoptosis. Could the He-wnt5A expressing cells be among them? Thorough examination of the posterior end of the metamorphosing larva revealed that the outermost posterior cells indeed are free of apoptosis (Fig. 3 C,D). As shown in Fig. 3D, diagonal microtome sections opened the sight into the extreme posterior tip, clearly showing this apoptosis-free region. The region is very small and comprises only very few cells. It could not be determined yet whether they are of ectodermal or entodermal nature.

In summary, the outermost tip of metamorphosing larvae has, therefore, a special quality, since it does not undergo apoptosis but expresses He-wnt5A and Hech-bra during metamorphosis.

\section{Grafting of the posterior region leads to secondary axis formation}

Based on the data of the in situ hybridization we went on to investigate the functional role of the He-wnt and Hech-bra expressing posterior region as a putative organizing center. Therefore, we stained donor larvae with neutral red, stimulated metamorphosis and, subsequently, used their posterior tips as transplant in grafting experiments.

Prior to the transplantation experiments we investigated the developmental potential of the He-wnt5A and Hech-braexpressing posterior region. Therefore, $3 \mathrm{~h}$ induced animals were cut in different sized anterior and posterior fragments and were left to finish metamorphosis. We could not observe any regeneration of the missing posterior or anterior end. However, after $24 \mathrm{~h}$ nearly all fragments had developed specific adult features depending on the respective larval part: hypostomes with tentacles out of posterior fragments, and stolon plates with a body column out of the anterior

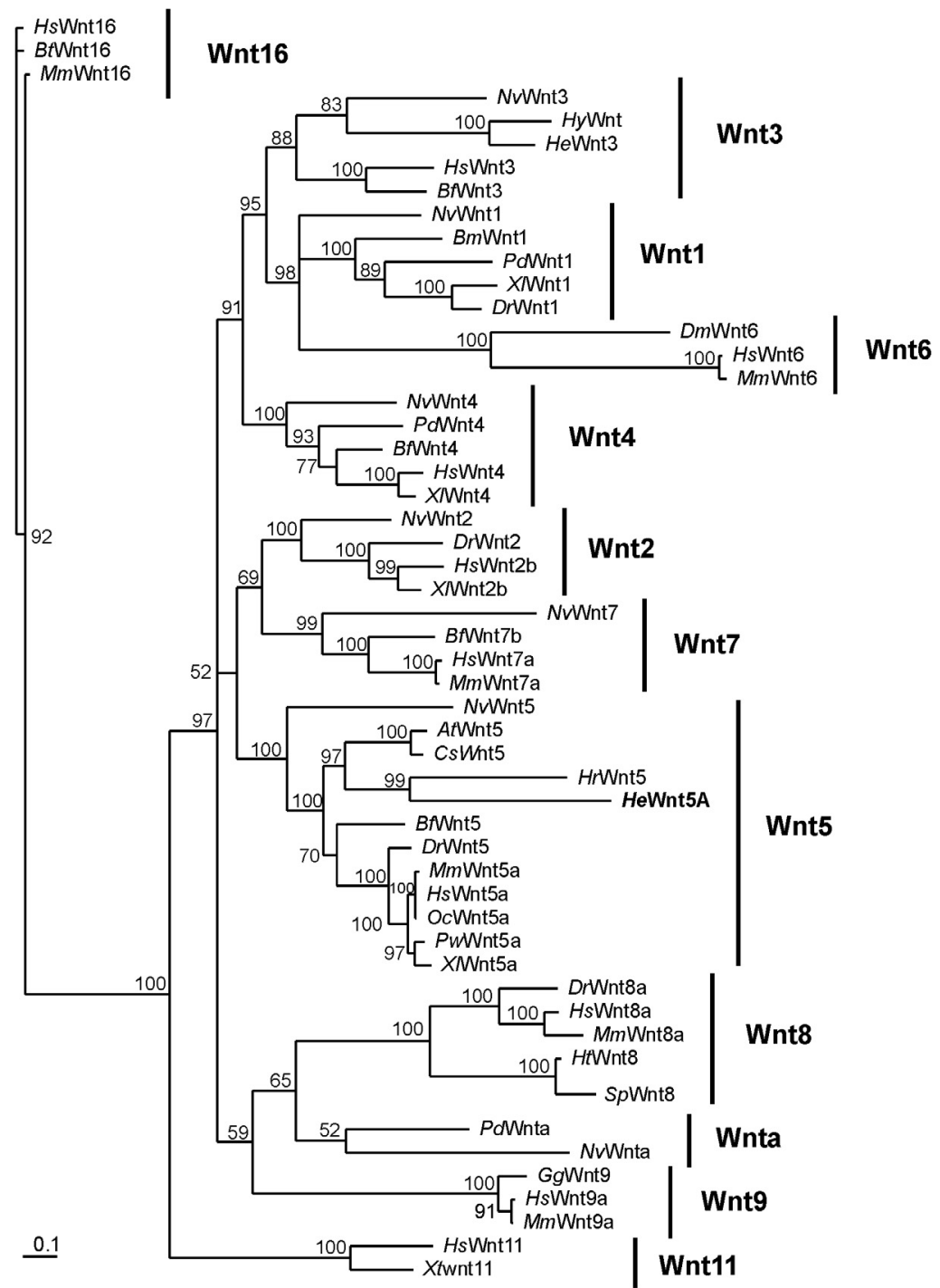

Fig. 2. Bayesian inference consensus tree of Wnt proteins showing the novel He-Wnt5A to cluster with Wnt5 and Wnt5A group of other species. NV Nematostella vectensis; Pd Platynereis dumerilii; XI Xenopus laevis; $B m$ Bombyx mori; Dr Danio rerio; Hs Homo sapiens; Hv Hydra vulgaris; He Hydractinia echinata; Bf Branchiostoma floridae; At Achaearanea tepidariorum; Cs Cupiennius salei; $\mathrm{Hr}$ Halocynthia roretzi; Pw Pleurodeles waltlii; Oc Oryctolagus cuniculus; Mm Mus musculus; Dm Drosophila melanogaster; Sp Strongylocentrotus purpuratus; $\mathrm{Ht}$ Heliocidaris tuberculata; $G g$ Gallus gallus; Xt Xenopus tropicalis; Bt Bos taurus. NvWnt1 (AAT00640.1); PdWnt1 (CAD37164.1); XIWnt1 (P10108); BmWnt1 (P49340); DrWnt1 (P24257); NvWnt2 (AAW28132.1); DrWnt2 (092048); HsWnt2b (093097); XIWnt2b (P87387); HyWnt (AAG13666.1); HeWnt3 (CAK50826.1); NvWnt3 (ABF48092.1); HsWnt3 (AAG38657.1); BfWnt3 (AAL37555.1); HsWnt4 (BAC23080.1); PdWnt4 (CAD37166.1); BfWnt4 (AAC80431.1); NvWnt4 (AAV87174.1); XIWnt4 (P49338); NvWnt5 (AAW28133.1); AtWnt5 (BAD12588.1); DrWnt5 (AAA96519.1); CsWnt5 (CAC87041.1); BfWnt5 (AAL37556.1); HrWnt5 (015978); HeWnt5 (AJ512409); PwWnt5a (O13267); HsWnt5a (AAH74783.2); OcWnt5a (ABD47459.1); XIWnt5a (P31286); MmWnt5a (P22725); HsWnt6 (AAG45154.1); MmWnt6 (P22727); DmWnt6 (NP_609108.1); NvWnt7 (AAV87176.1); HsWnt7a (O00755); MmWnt7a (P24383); BfWnt7b (AAC80433.1); SpWnt8 (AAR97610.1); HtWnt8 (AAS18256.1); DrWnt8a (P51028); HsWnt8a (O9H1J5); MmWnt8a (064527); GgWnt9 (042280); HsWnt9a (014904); MmWnt9a (O8R5M2); HsWnt11 (CAA73223.1); XtWnt11 (NP_001008133.1); PdWnta (CAD37169.1); NvWnta (AAT02182.1); HsWNT16 (AAD38052.1); BtWNT16 (Q5E9U6); MmWNT16 (AAD49352.2). 

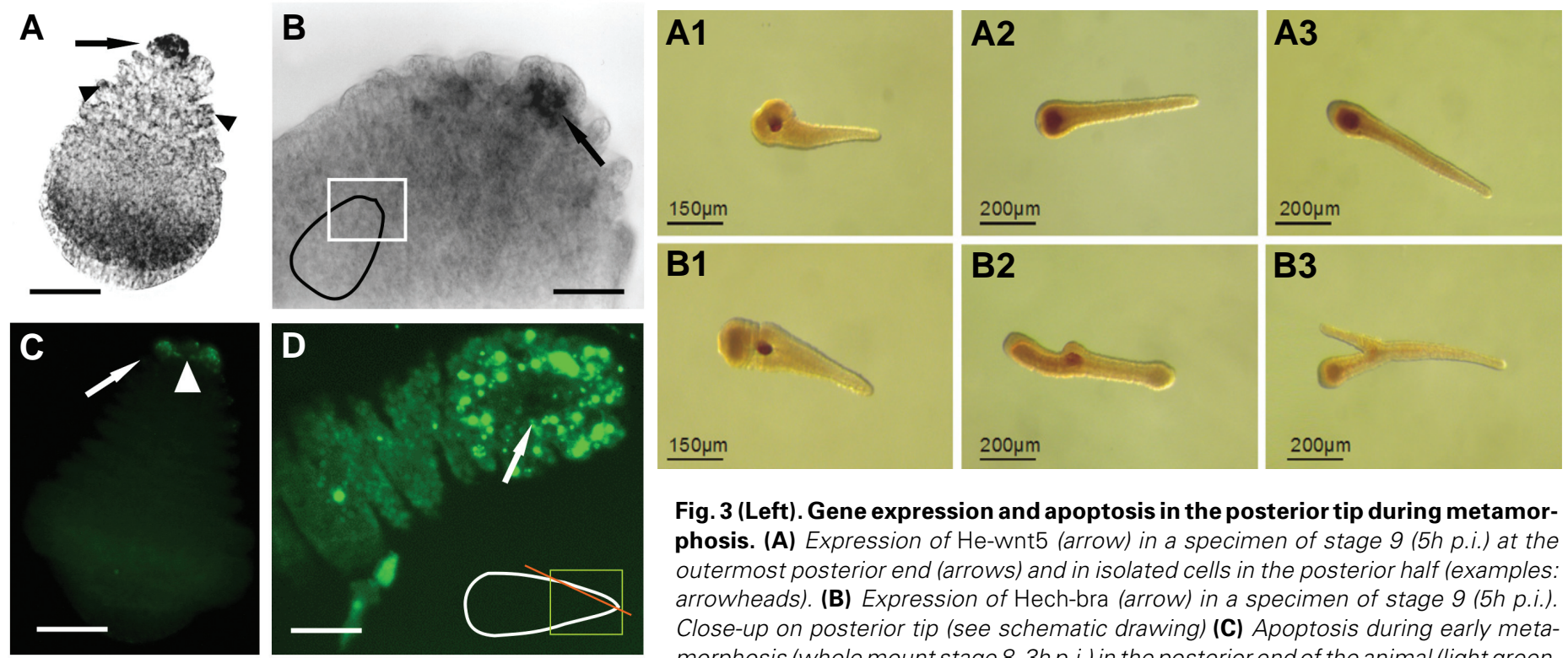

Fig. 3 (Left). Gene expression and apoptosis in the posterior tip during metamorphosis. (A) Expression of He-wnt5 (arrow) in a specimen of stage 9 (5h p.i.) at the outermost posterior end (arrows) and in isolated cells in the posterior half (examples: arrowheads). (B) Expression of Hech-bra (arrow) in a specimen of stage 9 (5h p.i.). Close-up on posterior tip (see schematic drawing) (C) Apoptosis during early metamorphosis (whole mount stage 8, 3h p.i.) in the posterior end of the animal (light green, arrow). The central region of the posterior tip is apoptosis-free (arrowhead). (D) Diagonal cut, set through the posterior tip of a metamorphosing planula stage 7 (2 h p.i.) (for level of cutting (orange) and close-up see schematic drawing). Central cells (arrow) are free of TUNEL-positive signals caused by apoptotic DNA degradation (light green). Scale bars are $10 \mu \mathrm{m}$ in A, 100 $\mu \mathrm{m}$ in $B$ and $D$, and $15 \mu \mathrm{m}$ in $C$. White arrows indicate apoptosis free regions, black arrows indicate gene expression.

Fig. 4 (Right). Transplantation of posterior tips (red coloured tissue) taken from planulae $\mathbf{3}$ h p.i. into uninduced larvae. (A) Transplantation to the anterior part; (B) transplantation to the middle part; (1, 2, 3): 5 min, 24 hours, 72 hours after transplantation.

parts (data not shown). Neither hypostome nor tentacle structures developed from the posterior tip of approximately $50 \mu \mathrm{m}$ of size, demonstrating that this region is not specified for adult head structures at least at the time we used it in the transplantation studies (data not shown).

Through grafting the posterior tips into uninduced larvae, we could clearly identify an axis inducing effect (Fig. 4). Grafting of the most posterior part of a metamorphosing donor larva (3h p.i.) to the middle part of an uninduced host larva yielded the development of a secondary axis (Fig. 4B 1-3). Of 15 larvae in two
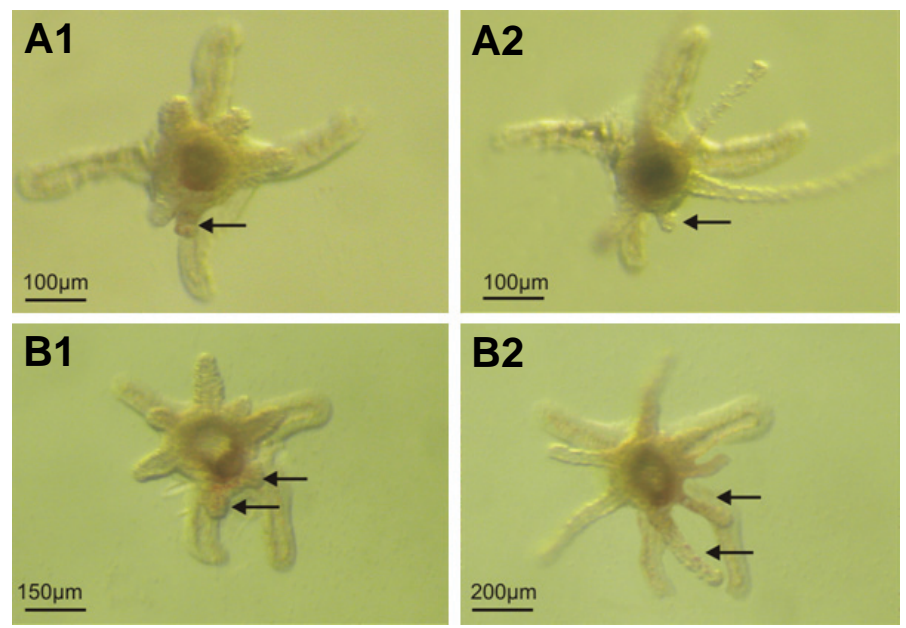

Fig. 5. Transplantation of posterior tips of planulae $3 \mathbf{h}$ p.i. into primary polyps $24 \mathrm{~h}$ old. (A1,B1) Specimens $48 \mathrm{~h}$ after transplantation. (A2,B2) Specimens 4 days after transplantation. Arrows indicate ectopic tentacles. respective independent experiments, all 30 larvae exhibited a more or less pronounced secondary axis. The tissue of this ectopic body axis was unstained, whereas the grafted tissue was still observable (confer e.g. Fig. 4 B2,B3), demonstrating that the ectopic tissue derived from stimulation of host-tissue rather than from merely growing grafts. Control transplantation of the same region to a more anterior part of an uninduced host larva, however, does not result in the induction of a secondary axis (Fig. 4A 1-3), suggesting a position-dependent effect. As negative controls, transplantations were performed using posterior tips of uninduced larvae and cellular material from a more anterior region of larvae $3 \mathrm{~h}$ p.i., which both do not show He-wnt5A expression. In no case hosts developed ectopic structures. Merely the developmental rate of the hosts slightly decreased.

Furthermore, we wanted to address the question whether the potential of the posterior tip to form a secondary axis is restricted to larval tissue, or if it can also be displayed in animals that already performed metamorphosis. We, therefore, transplanted the posterior tip of larvae $3 \mathrm{~h}$ in metamorphosis into the body column of adult primary polyps. As found for non-metamorphosing larvae, we could observe the induction of ectopic structures in those fully developed polyps 2-4 days after transplantation (Figs. 5, 6). However, in contrast to larvae, the polyps did not develop a completely functional secondary axis but grafting resulted in additional head structures, like tentacles along the body column. The ectopic structures always developed exactly at the site of the transplantation (recognizable by Neutral red colour) but were unstained, therefore proving their origin of growth-stimulated host tissue. Transplanted posterior tips of uninduced larvae never induced any ectopic structures.

In summary, we could demonstrate that the He-wnt5A and 
Hech-braexpressing / apoptosis-free region harbours the potential to induce axis formation and may therefore be comparable to organizing centres that occur during embryogenesis of higher eukaryotes like vertebrates.

\section{Discussion}

Organizing regions have been found in a wide variety of animals from cnidaria up to vertebrates. We here present a novel organizing region in the planulae of a marine hydrozoan, Hydractinia echinata. Most cnidaria develop through a planula larval stage. The metamorphosis of the planula to the polyp is an important stage during their life cycle. Upon stimulation by an external signal, the larva is activated from its morphogenetically inactive stage. This external signal is hypothesized to be transduced to an internal signal of the neuropeptide GLWamide family which then stimulates unknown target cells (Müller and Leitz 2002). During metamorphosis, cells differentiate, proliferate, die and migrate. Additionally, as we have shown here, an organizing region is activated.

The first hint to this organizing region was the localization of expression of He-wnt5A(this study) and a brachyurygene (Kroiher 1999 and this study) in the posterior part of metamorphosing larvae of Hydractinia. Some additional information to Wnt signalling was published previously. The complexity of the wingless group in Hydractinia is unknown, although very recently, a second Wnt clustering with Wnt3/3A was isolated from Hydractinia (Plickert et al. 2006), whereas our He-Wnt is similar to the Wnt5/5A type. Interestingly, the Hydractinia Wnt3/Wnt3A is also involved in formation of the primary body axis and is expressed in the posterior body region. The possible receptor for Wingless signalling molecules (Logan and Nusse 2004), Frizzled, has been investigated recently by Teo et al. (2005) also in Hydractinia echinata. Hefrizzledis expressed in larvae ready to metamorphose in the inner cell mass where first interstitial stem cells, nematoblasts, and neuroblasts appear, but cellular localization could not be done. It is unclear whether the Frizzled receptor identified by Teo et al. (2005) is actually addressed by the He-Wnt5A molecule identified in this investigation. It is also unknown whether the blocking of GSK-3 $\beta$, leading in adult polyps and colonies to an increase in positional value in terms of positional information (Müller et al. 2007 ) is due to the activation of either a Wnt3 or a Wnt5 signalling pathway. Head and bud formation were accompanied by the expression of Wnt3, frizzledand Tcf, also suggesting a role for wnt signalling pathways during head formation and involvement in the formation or maintenance of the mouth (Müller et al. 2007). Although the wnt5s of the anthozoan Nematostella vectensis and Hydractinia echinataare closely related (Fig. 2), wnt5 is expressed in the ectoderm in $H$. echinata and in the entoderm of $N$. vectensis planulae (Kusserow et al. 2005). It is unknown if this reflects different functions.

The positional expression of He-wnt5A and Hech-bra in the posterior tip led us to investigate whether this posterior region does have any inducing activity. We did this by transplanting the tip to different body regions of other larvae. The organizing region is only formed during metamorphosis, since it is not observed in posterior tips of non-induced animals. Posterior tips from uninduced larvae and small parts of regions other than extremely posterior did not induce secondary axes, indicating that the process of body axis formation during metamorphosis is distinct from that determining
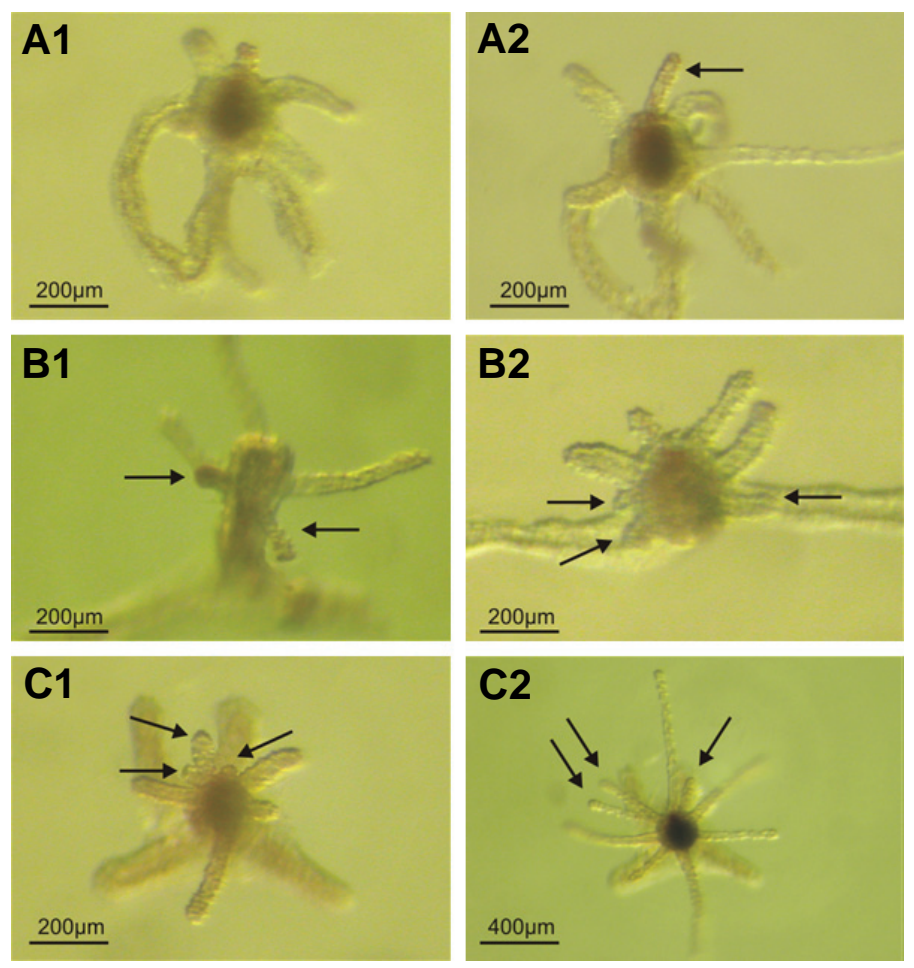

Fig. 6. Transplantation of posterior tips of planulae $3 \mathrm{~h}$ p.i. into $48 \mathrm{~h}$ old primary polyps . (A1,B1,C1) Specimens $48 \mathrm{~h}$ after transplantation. $(\mathbf{A} 2, \mathbf{B 2}, \mathbf{C 2})$ Specimens 4 days after transplantation. Arrows indicate ectopic tentacles.

larval tissue organization. This hypothesis is underlined by the fact that expression of He-wnt5A and Hech-bra 1) can be first identified at the onset of but not prior to metamorphosis. According to our data, this axis formation is not the result of intercalation or epimorphosis, but rather of induction, because the ectopic larval tails developed at the transplantation sites always derived from host tissue and not from labelled graft tissue. The ectopic tail was in every case free of label, whereas the graft could be identified by its Neutral red staining (cf. e.g. Fig. 4 B2).

Interestingly, the adult (polyp) tissue is still able to react to the organizing signal, as can be seen from ectopic head structure formation in adult polyps. This is in line with the organizing action of the hypostome in Hydra (Hobmayer et al. 2000; Broun et al. 2006) (note: the mouth of Hydractinia polyps develops at the posterior pole), but to our knowledge it is the first example of organizing effects of tissue derived from metamorphosing animals effective in larval as well as in adult tissue. Additionally, this raises the question whether the larva (at least with respect to the organizing center) can still be considered as "larval" after receiving the metamorphic signal. At present, only educated guesses could be possible but further studies on expression of developmental key genes will certainly help to elucidate this complex question.

From an evolutionary point of view the expression of both genes, winglessand brachyury, has a function in metamorphosis, but may also have acquired a function later in setting up the axis and specifying mesoderm. Alternatively, it could be that these genes already had an organizing as well as mesoderm specifying function in the common ancestors of the cnidaria and the bilateria (Martindale et al. 2004; Lee et al. 2006), and that nowadays axis formation still 
occurs whereas mesoderm specification is secondarily reduced. This secondary loss of mesodermal tissue by shortening the gastrulation processes would then support the hypotheses of Yanze et al. (2001) and Martindale et al. (2004) stating that diploblasty in the Cnidaria may be secondary.

Based on our and earlier data, we envision the following hypothesis: The bacterial signal is transduced by neurosensory cells to (an) internal neuropeptide(s) of the GLWamide family which signal(s) to unknown targets (Müller and Leitz 2002) and may directly or indirectly induce apoptosis. At the outermost posterior part several cells are not destined to die but express genes of the wingless and brachyury families, and maybe other genes unknown at date. All these processes might cooperate and seem to be necessary to organize and orchestrate further metamorphosis as well as the development of adult axis / head structures. A link to the induction of cell proliferation $6-8 \mathrm{~h}$ p.i. as shown by BrdU incorporation (Plickert et al. 1989) is currently not known. Our model is an alternative model to the one proposed by Freeman (2005), who hypothesized the existence of a stolon/hydranth inhibitor originating from the posterior tip, based on cutting experiments. However, He-wnt proteins do not seem to be suitable candidates for this inhibitor, because Wingless proteins are compounds generally acting paracrine and are not thought to travel the whole longitudinal axis.

The question, how the organizer described herein may control selective processes during metamorphosis, remains unsolved to date. At present, we still don't know whether it is involved in the fine tuning of the tissue reorganization at the posterior end, like the replacement of apoptotic cells, the growth of the adult neuronal network etc. According to our TUNEL results, the amount of cells spared from apoptotic death is quite small and may indeed resemble the mass expressing wingless and bachyury. In the future, colocalization of the expressed genes, or colocalization of TUNEL signals and gene expression will help to prove our hypothesis. Additionally, further refinement of the transplantation experiments will help to specify the inducing effects coming from the here described organizing cell mass.

Overall, our data provide evidence for a vital developmental role of a certain cell group in the posterior tip of metamorphosing Hydractinialarvae. A) There are at least three genes known to be expressed in the posterior tip, namely $\mathrm{He}$-wnt3and $\mathrm{He}$-wnt5A and Hech-bra, the orthologs of which are expressed in other organizers. B) We could show that the region expressing these genes is spared from programmed cell elimination during metamorphosis, and $\mathrm{C}$ ) we could demonstrate the induction of secondary axes by transplantation of this particular region into larvae and polyps. We, therefore, suggest the outermost posterior tip of metamorphosing Hydractinia larvae to be a developmental organizing center.

\section{Materials and Methods}

\section{Animals}

The animals were kept in a standard setting as described previously (Leitz and Wagner 1993; Müller and Leitz 2002). Artificial seawater (ASW) was prepared with commercial sea salt (Tropic Marine; Dreieich; Germany). It was changed daily in experiments involving larvae. Animals were fed 2-3 days old Artemia salina. Fertilized eggs were kept in glass dishes until they fully developed into mature planula larvae. The larvae used for experiments were $3-10$ days old. Induction of metamorphosis was performed by application of $116 \mathrm{mM}$ cesium chloride for 3 hours. Then, animals were washed and further incubated in ASW. Metamorphosing larvae are always termed as "xh post induction" (p.i.) in accordance with the time after application of the inducer. Development of planulae was recorded according to the stages defined in Seipp et al. (2007) and the animals were fixed at certain stages / time points p.i.

\section{Identification and localization of He-Wnt}

Wingless partial sequence information was found while screening a representative $\lambda$-phage cDNA library enriched for full length sequences. The $5^{\prime}$-end of $\mathrm{He}$-wntwas generated by PCR using this CDNA library as template with a standard T3-primer (Interactiva) as upstream primer and the wnt-specific 5'-CGCATACGGTAGATTGTCTCCG-3' (wnt1LP) located in the WNT (pfam00110) resp. WNT1 (smart00097) domain as downstream primer. The 3'fragment was identified by 3' RACE PCR using a UAP-linker coupled poly $d(T)$ primer (MWG Biotech) for reverse transcription and, subsequently, the wnt specific primer 5'GGAACACTTGGACGCACGTGC- 3' (wnt1-UP, WNT1 domain; smart00097) plus the adaptor primer UAP (MWG Biotech) for PCR. PCR inserts were cloned by TA cloning (Invitrogen) into a pCRII vector system and sequenced by Hot shot sequencing (Seqlab). The resulting sequences overlapped and were combined to a He-Wnt full length sequence. The nucleotide sequence was deposited in the EMBL database under accession number [AJ512409].

\section{Phylogenetic analysis of He-wnt5A}

Protein sequences were from NCBI (http://www.ncbi.nlm.nih.gov/) and SWISSPROT (http://expasy.org/sprot/). The DNA-sequence was translated with Bioedit (http://www.mbio.ncsu.edu/BioEdit/bioedit.html) to the protein sequence. Next matches were identified with BLAST (http://www.ncbi.nlm.nih.gov/BLAST/) and included in the phylogenetic analysis.

Conserved WNT-domains were identified by means of SMART (http://smart.emblheidelberg. de/) and used as a support during postprocessing of the alignments. Protein sequences were aligned with ClustalW (http://www.ebi.ac.uk/clustalw/) und Bioedit. Besides the recommended settings of the gap-penalties (Hall 2001) alternative alignments with varying gap-penalties were performed. Additionally, all positions with more than 50 gaps were eliminated. The signal peptide was deleted. All different alignments yielded nearly identical results (PRINTS: [PR01349, wnt-motive -CHGVS-within motif 4]; BLOCKS: within IPB005816D]).

For phylogenetic analysis Bayesian interference calculations with MrBayes 3.1.2 (http://mrbayes.csit.fsu.edu/) were performed. As an outgroup served HsWnt 16 (Wnt16, Homo sapiens). The substitution model Jones-Taylor-Thornten was chosen (Jones et al., 1992). Further parameter settings (Monte Carlo Markov chain): Mcmcp samplefreq $=10$ printfreq $=100$ nchains $=6$ savebrlens $=$ yes ngen $=1000000$.

\section{In situ hybridization}

The in situprobe was generated from the original clone isolated from the cDNA-library in the following way: Plasmid DNA containing the fragment of the He-wnt-gene was used as a template in a standard PCR reaction using 5'-CAACGAAGCTGGCCGATGGGC-3' and 5'GGTGACGGCATATTTGGAACAC-3' (Thermo Hybaid) as primers. This fragment was selected according to the putative amino acid sequence representing the WNT and WNT1 domains (WNT: pfam00110, resp. WNT1: smart00097) including the highly conserved WNT-sequence -CHGVS- (PRINTS: wntmotif4). The resulting $325 \mathrm{bp}$ fragment was cloned into a pCRII Vector system, and selected clones were sequenced to confirm the direction and sequence of the insert. Runoff in vitro transcription was performed using $\mathrm{Xhol}$ or $\mathrm{BamH}$ linearized recombinant plasmids. T7/SP6 Polymerases were used to create sense and anti-sense ssRNAs using the DIG-RNA-labelling kit (Roche, Mannheim, Germany). Specimens induced to metamorphose for 3 
hours were used. The in situprocedure was done as described earlier (Gajewski et al. 1996).

\section{TUNEL staining of whole mounts}

Cells exhibiting apoptosis were stained by using the slightly modified in situcell death detection kit (Roche, Mannheim). The method was as described earlier (Seipp et al. 2001, 2006).

\section{Histology}

Larvae or metamorphosing animals were embedded in Technovit 8100 plastics (Heraeus Kulzer) and cut with an ultra microtome (LKB) at $500 \mathrm{~nm}$. Slides were either embedded or treated with TUNELstaining (in situcell death detection kit, Roche) to detect apoptotic cells (Seipp et al. 2001, 2006), with emphasis on inclined serial cuts of the posterior tip.

\section{Transplantation studies}

Prior to transplantation the donor animals were stained with $0.1 \%$ neutral red in ASW, for 5 minutes, and then washed until no dye was dissolving. As control for normal behaviour of stained animals, metamorphosis was induced. In no case, neutral red staining caused any interference with normal life functions or the metamorphosis process (data not shown). The posterior tip ( $50 \mu \mathrm{m}$ in length) of stained donors $3 \mathrm{~h}$ in metamorphosis was cut off and served as transplant. In nonmetamorphosing host larvae a hole-like wound was caused using a tungsten needle. The graft was transferred into the wound of the host with the aid of a pulled glass capillary $(60-100 \mu \mathrm{m}$ tip diameter). After wound healing, successfully incorporated grafts could be identified by their red colour.

\section{Acknowledgments}

We thank Prof. Dr. Beate Brand-Saberi for her readiness to help with the tungsten needles and the transplantation studies. We also thank Prof. Günter Plickert and Dr. Michael Kroiher (University of Cologne) for the kind donation of the Hech-bra clone. Thanks are also due to Dr. Harald Fuge (Kaiserslautern) and Prof. Dr. Dietrich K. Hoffmann (Bochum) for help with histological techniques.

\section{References}

BIELEN H, OBERLEITNER S, MARCELLINI S, GEE L, LEMAIRE P, BODE HR, RUPP R and TECHNAU U (2007). Divergent functions of two ancient Hydra Brachyury paralogues suggest specific roles for their C-terminal domains in tissue fate induction. Development 134: 4187-4197.

BROUN M, GEE L, REINHARDT B and BODE HR (2005). Formation of the head organizer in hydra involves the canonical Wnt pathway. Development 132: 2907-2916

BROWNE EN (1908). The production of new hydranths in hydra by the insertion of small grafts. J Exp Zoo/8: 1-33.

GAJEWSKI M, LEITZ T, SCHLOSSHERR J and PLICKERT G (1996). LWamides from Cnidaria constitute a novel family of neuropeptides with morphogenetic activity. Roux's Arch Dev Bio/205: 232-242.

GUDER C, PHILLIP I, LENGFELD T, WATANABE H, HOBMAYER B. and HOLSTEIN TW (2006). The Wnt code: cnidarians signal the way. Oncogene 25: $7450-7460$

FREEMAN G (2005). The effect of larval age on developmental changes in the polyp prepattern of a hydrozoan planula. Zoology 108: 55-73.

HALL, B-G. (2001). Phylogenetic Trees Made Easy. Sinauer Associates, Inc., Publishers Sunderland, Massachusetts, USA.

HOBMAYER B, RENTZSCH F, KUHN K, HAPPEL CM, CRAMER VON LAUE C, SNYDER P, ROTHBÄCHER U and HOLSTEIN TW (2000). Wnt signalling molecules act in axis formation in the diploblastic metazoan Hydra. Nature 407: 186-189.

JONES DT, TAYLOR WR and THORNTON JM (1992). The rapid generation of mutation data matrices from protein sequences. Comp App/ Biosci 8: 275282.

KROIHER M (1999) Temporal and spatial expression of Hech-bra, a brachyury homologue from Hydractinia echinata. 8th intl. Workshop on Hydroid Development, pp. 25 (Abstr.).

KUSSEROW A, PANG K, STURM C, HROUDA M, LENTFER J, SCHMIDT HA, TECHNAU U, VON HAESELER A, HOBMAYER B, MARTINDALE MQ and HOLSTEIN TW (2005). Unexpected complexity of the Wnt gene family in a sea anemone. Nature 433: 156-160.

LEE PN, PANG K, MATUS DQ and MARTINDALE MQ (2006). A WNT things to come: Evolution of Wnt signalling and polarity in cnidarians. Sem Cell Dev Bio/17: 157-167.

LEITZ T (1997). Induction of settlement and metamorphosis of Cnidarian larvae: signals and signal transduction. Inv Reprod Dev 31: 109-122.

LEITZ T, WAGNER T (1993). The marine bacterium Alteromonas espejiana induces metamorphosis of the hydroid Hydractinia echinata. Mar Biol 115: 173-178.

LEMAIRE P, KODJABACHAIN L. (1996). The vertebrate organizer: structure and molecules. Trends Genetics 12: 525-531.

LOGAN CY, NUSSE R (2004). The wnt signalling pathway in development and disease. Annu Rev Cel/ Dev Bio/20: 781-810.

MARTINDALE M, PANG MK and FINNERTY JR (2004). Investigating the origins of triploblasty: "mesodermal" gene expression in a diploblastic animal, the sea anemone Nematostella vectensis (phylum, Cnidaria; class, Anthozoa). Development 131: 2463-2474.

MÜLLER WA (1969). Auslösung der Metamorphose durch Bakterien bei den Larven von Hydractinia echinata. Zool Jb Anat 86: 84-95

MÜLLER WA, LEITZ T (2002). Metamorphosis in the cnidaria. Can J Zoo/ 80 1755-1771.

MÜLLER WA, FRANK U, TEO R, MOKADY O, GUETTE C and PLICKERT G (2007). Wnt signaling in hydroid development: ectopic heads and giant buds induced by GSK-3 $\beta$ inhibitors. Int J Dev Bio/51: 211-220.

NIEHRS C (2001). The Spemann organizer and embryonic head induction. EMBO J20: 631637

NIEHRS C (2004). Regionally specific induction by the Spemann-Mangold organizer. Nat Rev Genet 5: 425-434.

NUSSE R (2005). Wnt signalling in disease and development. Cell Res 15: 18 32.

PLICKERT G, KROIHER M and MUNCK A (1988). Cell proliferation and early differentiation during embryonic development and metamorphosis of Hydractinia echinata. Development 103: 795-803.

PLICKERT G, JACOBY V, FRANK U, MÜLLER WA and MOKADY O (2006). Wnt signaling in hydroid development: Formation of the primary body axis in embryogenesis and its subsequent patterning. Dev Bio/298: 368-378.

RENTZSCH F, GUDER C, VOCKE D, HOBMAYER B, and HOLSTEIN TW (2007). An ancient chordinlike gene in organizer formation in hydra. Proc Natl. Acad. Sci. USA 104: 3249-3254.

ROBB L, TAM PPL (2004). Gastrula organizer and embryonic patterning in the mouse. Seminars Cell Dev Bio/15: 543-554.

SANDER, K. and FAESSLER, P.E. (2001). Introducing the Spemann-Mangold organizer: experiments and insights that generated a key concept in developmental biology. Int. J. Dev. Biol. (2001). 45: 1-11.

SEIPP S, SCHMICH J and LEITZ T (2001). Apoptosis - a death inducing mechanism tightly linked with morphogenesis in Hydractinia echinata (Cnidaria, Hydrozoa). Development 128: 4891-4898.

SEIPP S, WITTIG K, STIENING B, BÖTTGER A and LEITZ T (2006). Metamorphosis of Hydractinia echinata (Cnidaria) is caspase-dependent. Int J Dev Bio/50: 63 -70.

SEIPP S, SCHMICH J, KEHRWALD T and LEITZ T (2007). Metamorphosis of Hydractinia echinata - natural versus artificial induction and developmental plasticity. Dev Genes Evol217: 385-394

SMITH J (1999). T-box genes: what they do and how they do it. Trends Genet 15 154-158.

SPEMANN H, MANGOLD, H (1924). Über Induktion von Embryonalanlagen durch Implantation artfremder Organisatoren. Arch f Mikr Anat Entw Mech 
100: 599-638. English edition re-edited in 2001, incorporating corrections by Spemann in the following paper:

SPEMANN, $\mathrm{H}$ and MANGOLD H. (2001) Induction of embryonic primordia by implantation of Organizers from a different species. Int. J. Dev. Biol. 45: 1338

TECHNAU U, BODE HR (1999). HyBra1, a Brachyury homologue, acts during head formation in Hydra. Development 126, 999-1010.
TEO R, MÖHRLEN F, PLICKERT G, MÜLLER WA and FRANK U (2005). An evolutionary conserved role of Wnt signalling in stem cell fate decision. Dev Biol 289: 91-99.

YANZE N, SPRING J, SCHMIDLI C and SCHMID V (2001). Conservation of Hox/ ParaHox-related genes in the early development of a cnidarian. Dev Bio/236: 89-98.

\section{Further Related Reading, published previously in the Int. J. Dev. Biol.}

See Special Issue Pattern Formation edited by Michael K. Richardson and Cheng-Ming Chuong at: http://www.ijdb.ehu.es/web/contents.php?vol=53\&issue=5-6

\section{Induction of reverse development in two marine Hydrozoans}

Jürgen Schmich, Yulia Kraus, Doris De Vito, Daria Graziussi, Ferdinando Boero and Stefano Piraino

Int. J. Dev. Biol. (2007) 51: 45-56

\section{Morphomechanical programming of morphogenesis in Cnidarian embryos Yulia A. Kraus}

Int. J. Dev. Biol. (2006) 50: 267-275

Patterning a multi-headed mutant in Hydractinia: enhancement of head formation and its phenotypic normalization

Werner A Müller, Regina Teo and Frank Möhrlen

Int. J. Dev. Biol. (2004) 48: 9-15

Autoaggressive, multi-headed and other mutant phenotypes in Hydractinia echinata (Cnidaria: Hydrozoa)

Werner A Müller

Int. J. Dev. Biol. (2002) 46: 1023-1033

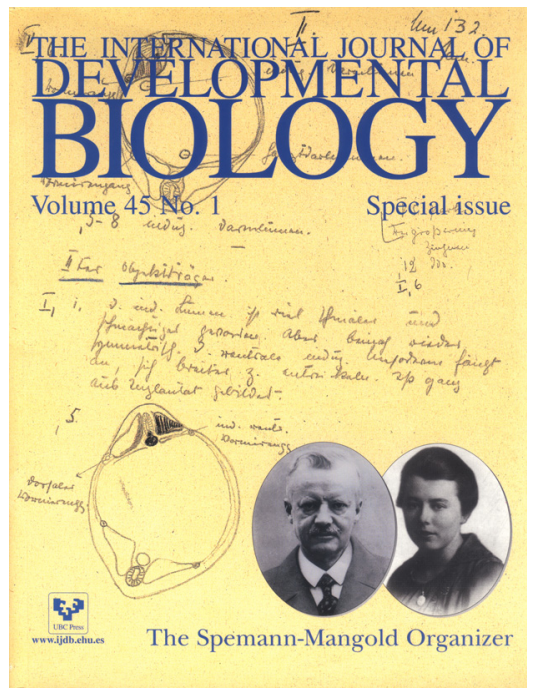

5 yr ISI Impact Factor $(2008)=3.271$

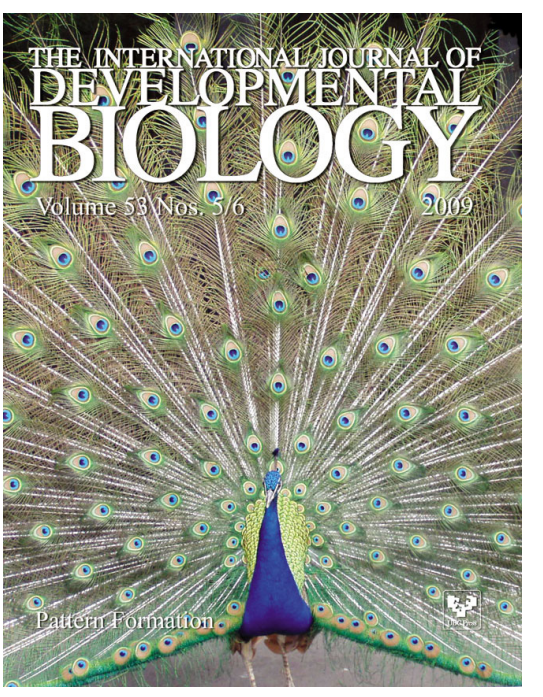

